\title{
Abdominal Desmoid Tumors: Hands Off?
}

\author{
Danique L. M. van Broekhoven, MD, Dirk J. Grunhagen, MD, PhD, and Cornelis Verhoef, MD, PhD \\ Department of Surgical Oncology, Erasmus MC Cancer Institute, Rotterdam, The Netherlands
}

The reported incidence of desmoid tumors (DT) seems to increase from about two cases per million people in 1993 to about five cases per million people in $2013 .{ }^{1}$ Because it lacks the ability to metastasize, a desmoid tumor is classified as a benign disorder. Nevertheless, the sequelae of this disease and the applied treatments may be underlined by the fact that patients with familial adenomatous polyposis (FAP) may die from the consequences of DT. Moreover, substantial morbidity due to invasive growth is frequently seen. Because of the poor understanding of the natural history of the disease, its tumor biology, and the lack of randomized studies comparing different treatment options, the recommended treatment options vary widely depending on tumor aggressiveness, location, patient wish, and preferences of the treating physicians.

With respect to the existing treatment options, surgery has been the cornerstone in treating DT. The reported recurrence rate after resection varies greatly, from 5 to $63 \%$, with most studies reporting recurrence rates of approximately $20 \% .^{2-9}$ The prognostic value of several characteristics has been investigated. The reported results about the importance of age, location, resection margins, and adjuvant radiotherapy are conflicting. ${ }^{4,70-12}$ Also, radiotherapy has been widely applied for DT, both in primary and adjuvant settings. Results have been ambiguous, especially for adjuvant radiotherapy. ${ }^{4,8,11,13}$ A study by Keus et al. addressed the role of radiotherapy in a primary setting. They reported partial and complete response in $50 \%$ of patients and durable stable disease in $41 \%$ of patients, with a local control rate of $81 \%$ at 3 years. ${ }^{14}$ Literature on systemic treatment for DT is heterogeneous and limited. Antihormonal drugs, nonsteroid anti-

(C) Society of Surgical Oncology 2016

First Received: 15 February 2016;

Published Online: 8 March 2016

C. Verhoef, MD, PhD

e-mail: c.verhoef@erasmusmc.nl inflammatory drugs, chemotherapy, and tyrosine kinase inhibitors have all been applied using different regimens. Most studies consist of relatively small cohorts, rendering it difficult to put results into perspective. Prospective trials are currently running with sorafenib (NCT 02066181), pazopanib (NCT01876082), sirolimus (NCT 01265030), and PF-03084014 (NCT01981551), and their results are eagerly awaited. Isolated limb perfusion is reserved for patients with advanced disease without the possibility of limb preservation in case of surgery. This procedure is only performed in specialized centers. Three European Organization for Research and Treatment of Cancer sarcoma centers reported good results, with limb preservation rates up to $88 \% .{ }^{15}$ Key questions in managing DT are when and how to treat. Importantly, expected benefits from therapy should be well balanced against potential treatment-induced untoward effects.

Recent years have seen a growing interest in a wait-andsee approach for patients presenting with DT, an approach prompted by observations of spontaneous regressions and durable disease stabilization. ${ }^{3,4,16}$

The study by Burtenshaw et al. published in this issue of Annals of Surgical Oncology substantially adds to our knowledge of the wait-and-see approach of abdominal DT - that is, abdominal wall (AW) and intra-abdominal (IA) DT ${ }^{17}$ Most studies have mingled IA tumors, tumors on the trunk, extremities, and head/neck, primary and recurrent lesions, FAP and non-FAP related, and pregnancy related. These heterogeneous populations lead to conflicting reports regarding the biology and management of these tumors. Burtenshaw et al. clearly recognized this problem; they focused on abdominal DT only and stratified for primary and recurrent disease. They concluded that since the wait-and-see approach had been implemented for abdominal DT at their institution, over half of patients observed required no intervention with prolonged follow-up. Furthermore, tumors less than $7 \mathrm{~cm}$ at presentation and AW DT were favorable prognostic factors in this study. The 
need for surgical intervention in asymptomatic patients is questionable.

A possible drawback of the current study of Burtenshaw et al. is that IA and AW DT, with or without FAP or pregnancy, were analyzed as one entity. Most publications on this topic group extra-abdominal, IA, and AW tumors together. However, there is growing evidence that patients with AW tumors have excellent outcomes regardless of treatment strategy and that IA and AW DT likely have different inherent biology. It is thus likely that this is not a single entity to treat; as a consequence, IA DT needs a different treatment approach than AW DT. For example, in surgery, morbidity and recurrence rates are significantly different between AW DT and IA DT; recurrence rates and morbidity in IA are significant higher, and even mortality is reported. Additionally, within the IA DT, there is a difference between FAP DT and non-FAP-related DT. In several publications describing FAP-associated IA DT, surgical resection is associated with morbidity rates of 22$60 \%$, perioperative mortality rates of up to $36 \%$, and recurrence rates of $65-88 \% .^{18-21}$ Non-FAP-associated IA DT can be resected with low morbidity and mortality in specialist centers and is associated with low rates of local recurrence. ${ }^{21}$ Moreover, FAP-associated DT harbor more genetic changes compared to sporadic DT. ${ }^{22}$ A recent study by Huss et al. investigated genetic and clinicopathologic features of IA DSs. ${ }^{23}$ They found a difference in biology, as IA tumors were solid, bulky, and localized, and they originated from the mesentery. Extra-abdominal and AW tumors, however, were flat and grew in an infiltrating manner. In addition, molecular characteristics may also differ: many IA tumors showed CTNNB1 mutation, especially T41A, a subtype associated with a low recurrence risk. $^{24-26}$ Last, patient characteristics are different. IA tumors presented mostly in men with a median age of 50, whereas the extra-abdominal and AW tumors have a threefold increased incidence in women with a median age of 35 years. The above-mentioned findings suggest that (non-)FAP-associated IA or AW DT may have different tumor biology and should therefore be treated as a distinct entity. This difference is probably also present in pregnancy and non-pregnancy-related DT. ${ }^{27}$

Biological behavior and how to predict it remains a subject for future studies. Several study groups are investigating the tumor behavior under a wait-and-see policy in a prospective manner (NCT01801176, NCT02547831). ${ }^{28}$ This information will provide further guidance to an individualized treatment strategy. In the recent European DT consensus, all major types and locations are included, different treatments are advised on the basis of tumor location, and IA tumors are included and regarded as different from all other types of locations, in line with World Health Organization classification. ${ }^{29,30}$
DT remain challenging. A staging system that stratifies patients according to the severity of disease is a prerequisite to understanding the natural history of the disease, to compare treatments, and to delineate guidelines for a peculiar disease (as DT is). An attempt has been done by the Collaborative Group of the Americas on Inherited Colorectal Cancer (CGA-ICC) in 2005 for the management of patients with IA DT. ${ }^{31}$ Additional variables may interact with outcome, such as FAP, pregnancy associated, or $\beta$-catenin status. Larger multi-institutional experience must be gathered in the future for patients with DT; these would be able to provide a more accurate assessment of different sites and clinicopathologic features as it pertains to outcome. This large study by Burtenshaw et al. contains important information and will help unravel the mysterious ways of DT.

CONFLICT OF INTEREST The authors declare no conflict of interest.

\section{REFERENCES}

1. van Broekhoven DL, Grünhagen DJ, den Bakker MA, van Dalen $\mathrm{T}$, Verhoef $\mathrm{C}$. Time trends in the incidence and treatment of extra-abdominal and abdominal aggressive fibromatosis: a population-based study. Ann Surg Oncol. 2015;22(9):2817-23.

2. Salas S, Dufresne A, Bui B, Blay JY, Terrier P, Ranchere-Vince $\mathrm{D}$, et al. Prognostic factors influencing progression-free survival determined from a series of sporadic desmoid tumors: a wait-andsee policy according to tumor presentation. J Clin Oncol. 2011;29:3553-8.

3. Fiore M, Rimareix F, Mariani L, Domont J, Collini P, Le Pechoux C, et al. Desmoid-type fibromatosis: a front-line conservative approach to select patients for surgical treatment. Ann Surg Oncol. 2009;16:2587-93.

4. Baumert BG, Spahr MO, Von Hochstetter A, Beauvois S, Landmann $\mathrm{C}$, Fridrich $\mathrm{K}$ et al. The impact of radiotherapy in the treatment of desmoid tumours. An international survey of 110 patients. A study of the Rare Cancer Network. Radiat Oncol. 2007;2:12.

5. Mankin HJ, Hornicek FJ, Springfield DS. Extra-abdominal desmoid tumors: a report of 234 cases. J Surg Oncol. 2010;102: $380-4$.

6. Lev D, Kotilingam D, Wei C, Ballo MT, Zagars GK, Pisters PWT, et al. Optimizing treatment of desmoid tumors. J Clin Oncol. 2007;25:1785-91.

7. Huang K, Fu H, Shi YQ, Zhou Y, Du CY. Prognostic factors for extra-abdominal and abdominal wall desmoids: a 20 -year experience at a single institution. J Surg Oncol. 2009;100:563-9.

8. Guadagnolo BA, Zagars GK, Ballo MT. Long-term outcomes for desmoid tumors treated with radiation therapy. Int J Radiat Oncol Biol Phys. 2008;71:441-7.

9. van Broekhoven DL, Verhoef C, Elias SG, Witkamp AJ, van Gorp JM, van Geel BA, et al. Local recurrence after surgery for primary extra-abdominal desmoid-type fibromatosis. $\mathrm{Br} J$ Surg. 2013;100:1214-9.

10. Stoeckle E, Coindre JM, Longy M, Binh MB, Kantor G, Kind M, et al. A critical analysis of treatment strategies in desmoid tumours: a review of a series of 106 cases. Eur J Surg Oncol. 2009;35:129-34. 
11. Gluck I, Griffith KA, Biermann JS, Feng FY, Lucas DR, BenJosef E. Role of radiotherapy in the management of desmoid tumors. Int J Radiat Oncol Biol Phys. 2011;80:787-92.

12. Crago AM, Denton B, Salas S, Dufresne A, Mezhir JJ, Hameed $\mathrm{M}$, et al. A prognostic nomogram for prediction of recurrence in desmoid fibromatosis. Ann Surg. 2013;258:347-53.

13. Ballo MT, Zagars GK, Pollack A, Pisters PWT, Pollack RA. Desmoid tumor: prognostic factors and outcome after surgery, radiation therapy, or combined surgery and radiation therapy. $J$ Clin Oncol. 1999; 17:158-67.

14. Keus RB, Nout RA, Blay JY, de Jong JM, Hennig I, Saran F, et al. Results of a phase II pilot study of moderate dose radiotherapy for inoperable desmoid-type fibromatosis-an EORTC STBSG and ROG study (EORTC 62991-22998). Ann Oncol. 2013;24:2672-6.

15. van Broekhoven DL, Deroose JP, Bonvalot S, Gronchi A, Grünhagen DJ, Eggermont AM, et al. Isolated limb perfusion using tumour necrosis factor $\alpha$ and melphalan in patients with advanced aggressive fibromatosis. Br J Surg. 2014;101:1674-80.

16. Mitchell G, Thomas JM, Harmer CL. Aggressive fibromatosis: evidence for a stable phase. Sarcoma. 1998;2:149-54.

17. Burtenshaw SM, Cannell AJ, McAlister ED, Siddique S, Kandel $\mathrm{R}$, Blackstein ME, et al. Toward observation as first-line management in abdominal desmoid tumors. Ann Surg Oncol. doi:10. 1245/s10434-016-5159-6.

18. Melis M, Zager JS, Sondak VK. Multimodality management of desmoid tumors: how important is a negative surgical margin? $J$ Surg Oncol. 2008;98:594-602.

19. Phillips SR, A'Hern R, Thomas JM. Aggressive fibromatosis of the abdominal wall, limbs and limb girdles. $\mathrm{Br} J$ Surg. 2004;91:1624-9.

20. Middleton SB, Phillips RK. Surgery for large intra-abdominal desmoid tumors: report of four cases. Dis Colon Rectum. 2000;43:1759-62.

21. Wilkinson MJ, Fitzgerald JE, Thomas JM, Hayes AJ, Strauss DC. Surgical resection for non-familial adenomatous polyposis-related intra-abdominal fibromatosis. Br J Surg. 2012;99: 706-13.

22. Robanus-Maandag E, Bosch C, Amini-Nik S, Knijnenburg J, Szuhai K, Cervera P, et al. Familial adenomatous polyposis- associated desmoids display significantly more genetic changes than sporadic desmoids. PLoS One. 2011;6:e24354.

23. Huss S, Nehles J, Binot E, Wardelmann E, Mittler J, Kleine MA, et al. $\beta$-Catenin $(C T N N B 1)$ mutations and clinicopathological features of mesenteric desmoid-type fibromatosis. Histopathology. 2013;62:294-304.

24. Lazar AJ, Tuvin D, Hajibashi S, Habeeb S, Bolshakov S, Mayordomo-Aranda E, et al. Specific mutations in the beta-catenin gene $(C T N N B 1)$ correlate with local recurrence in sporadic desmoid tumors. Am J Pathol. 2008;173:1518-27.

25. Bo N, Wang D, Wu B, Chen L, Ma R. Analysis of $\beta$-catenin expression and exon 3 mutations in pediatric sporadic aggressive fibromatosis. Pediatr Dev Pathol. 2012;15:173-8.

26. van Broekhoven DL, Verhoef C, Grünhagen DJ, van Gorp JM, den Bakker MA, Hinrichs JW, et al. Prognostic falue of CTNNB1 gene mutation in primary sporadic aggressive fibromatosis. Ann Surg Oncol. 2015;22:1464-70.

27. Fiore M, Coppola S, Cannell AJ, Colombo C, Bertagnolli MM, George S, et al. Desmoid-type fibromatosis and pregnancy: a multi-institutional analysis of recurrence and obstetric risk. Ann Surg. 2014;259:973-8.

28. van Broekhoven DLM, Grünhagen DJ, van Dalen T, et al. Tailored beta-catenin mutational apporoach in extra-abdominal sporadic desmoid-type fibromatosis patients without therapeutic intervention. An Italian and Dutch initiative. BMC Cancer., submitted.

29. Kasper B, Baumgarten C, Bonvalot S, Haas R, Haller F, Hohenberger $\mathrm{P}$, et al. Management of sporadic desmoid-type fibromatosis: a European consensus approach based on patients' and professionals' expertise-a sarcoma patients EuroNet and European Organisation for Research and Treatment of Cancer/ Soft Tissue and Bone Sarcoma Group initiative. Eur J Cancer. 2015;51:127-36.

30. Fletcher CDM, Bridge JA, Hogendoorn P, Mertens F. WHO classification of tumours of soft tissue and bone. 4th ed. Geneva: World Health Organization; 2013.

31. Church J, Berk T, Boman BM, et al. Staging intra-abdominal desmoid tumors in familial adenomatous polyposis: a search for a uniform approach to a troubling disease. Dis Colon Rectum. 2005;48:1528-34. 